\title{
Comparative analysis of Mycobacterium tuberculosis-specific antigens and T-cell mitogen- stimulated interferon gamma production in hemodialysis patients and healthy individuals
}

Heechul Park

Catholic University of Pusan

Ye Na Kim

Kosin University Gospel Hospital

\section{Sung-Bae Park}

Catholic University of Pusan

Junseong Kim

Catholic University of Pusan

Jaewon Lim

Daegu Haany University

Jungho Kim

Catholic University of Pusan

Ji Young Park

Busan Medical Center

Sunghyun Kim ( $\nabla$ shkim0423@cup.ac.kr)

Catholic University of Pusan https://orcid.org/0000-0003-2511-6555

Research article

Keywords: Tuberculosis, Latent TB infection, Hemodialysis patients, Interferon gamma release assays, QuantiFERON-TB Gold In-Tube

Posted Date: August 5th, 2020

DOI: https://doi.org/10.21203/rs.3.rs-40897/v2

License: (9) (1) This work is licensed under a Creative Commons Attribution 4.0 International License. Read Full License 


\section{Abstract}

Background The incidence of Tuberculosis (TB) is higher in patients undergoing chronic hemodialysis than in the general population; further, both the incidence and development of active TB from latent TB infection (LTBI) are considerably higher in patients undergoing hemodialysis than in any other group. The QuantiFERON-TB Gold In-Tube (QFT-GIT) assay is one of the most commonly used interferon gamma (IFN- $\gamma$ ) release assays (IGRAs) currently. We aim to know T-cell function of hemodialysis patients and the possible QFT false negatives. Methods In order to analyze the MTB-specific antigen-stimulated IFN- $\gamma$ release in patients on hemodialysis, the QFT-GIT test was used in this study. A total of 84 hemodialysis patients and 52 healthy subjects were enrolled from Kosin University Gospel Hospital and Catholic University of Pusan, Busan, Republic of Korea; their whole blood samples were collected and used for the present study. Results The positivity results of the IGRAs in hemodialysis patients and normal subjects were 34/84 (40.4\%) and 4/52 (7.6\%), respectively. The mean value of MTB-specific antigen-stimulated IFN- $y$ in hemodialysis patients with LTBI and non-LTBI status in hemodialysis patients, healthy individuals were $1.85 \mathrm{IU} / \mathrm{mL}(4.44 \mathrm{ng} / \mathrm{mL})$ and $0.028 \mathrm{IU} / \mathrm{mL}(0.067 \mathrm{ng} / \mathrm{mL})$ and $0.255 \mathrm{IU} / \mathrm{mL}(0.612 \mathrm{ng} / \mathrm{mL})$ respectively. In addition, Of the 34 LTBI status in hemodialysis patients, $14(41.2 \%)$ had T-cell mitogenstimulated IFN-y levels of 10 or less, and $20(58.8 \%)$ had 10 or more T-cell mitogen-stimulated IFN- $\gamma$. Moreover, Of the 49 non-LTBI status in hemodialysis patients, 19 (38.8\%) had T-cell mitogen-stimulated IFN- $\gamma$ levels of 10 or less, and 30 (61.2\%) showed T-cell mitogen-stimulated IFN- $\gamma$ levels of 10 or more. On the other hand, there was no low level of T-cell mitogen-stimulated IFN- $\gamma$ in the healthy individuals. Conclusion This reveals that T-cell function in hemodialysis patients was reduced as compared to the healthy individuals. Therefore, the cut-off value should be adjusted for the active TB high-risk group when using IGRA tests. The clinical manifestations of TB in patients on hemodialysis are quite non-specific, making timely diagnosis difficult, and delaying the initiation of curative treatment, delay being a major determinant of outcome.

\section{Background}

Tuberculosis (TB) is one of the top 10 causes of death worldwide, and the leading cause of death from a single infectious agent, Mycobacterium tuberculosis (MTB) [1]. There were 10 million new cases of TB worldwide in 2018-5.8 million men (58\%) and 3.2 million women (32\%) [2], and an estimated one million children; 230,000 children died of TB [3]. Globally, the absolute number of TB deaths among HIV-negative people has fallen by a best estimate of $29 \%$ since 2000 -from 1.8 million in 2000 to 1.3 million in 2017and by $5 \%$ since 2015 [3]. Diagnosis of MTB infection is an important factor in reducing the number of cases of TB in minimally affected countries, and many studies and experiments are still underway [4]. However, the Republic of Korea still has 33,796 TB patients, the highest rate among Organization for Economic Cooperation and Development (OECD) countries in 2018 [2]. Therefore, the fundamental challenge of how to optimize the evaluation of diagnostics for TB infection, for which there is currently no accurate diagnostic assessment, needs to be addressed [5]. 
The two main immunodiagnostic methods currently used for the diagnosis of LTBI are the tuberculin skin test (TST) [6] and the interferon gamma (IFN-Y) release assays (IGRAs) [7]. These tests work on the principle of in vivo and ex vivo cell-mediated immunity, respectively [8]. The TST is an intradermal injection of tuberculin purified protein derivatives (PPD) to identify the whole MTB Ag-specific immune response, delayed-type hypersensitivity. Nevertheless, it has been reported that the accuracy measures of TST are often confounded by the Bacillus Calmette Guérin (BCG) vaccination and nontuberculous mycobacteria (NTM) infections [9]. IGRA is an ex vivo whole blood test of the T-cell immune response that measures the T-cell release of IFN-y, an inflammatory cytokine, following stimulation by Ags specific to the MTB complex (MTC) including MTB, M. africanum, M. bovis, $M$. bovis BCG, M. orygis, M. microti, $M$. canetti, M. caprae, M. pinnipedii, M. sucricattae, and M. mungi [10]. MTB-specific Ags used in IGRAs, such as early secretory antigen target 6 (ESAT-6) and culture filtrate protein 10 (CFP-10), and TB 7.7 are not present in all $M$. bovis BCG strains or major environmental mycobacteria, NTMs, and are therefore specific for MTB and respond to T-cells that have had MTB bacteria in their blood [11-12]. The IGRAs have shown significant potential to reduce false positive results, particularly among BCG-vaccinated low-risk populations [10]. However, IGRAs have also been known to have limited sensitivity for immunocompromised individuals and young children. Furthermore, IGRAs cannot differentiate between active TB disease and LTBI [13].

End stage renal disease (ESRD) is known to compromise cellular immune function, and patients on hemodialysis have been shown to have T-cell dysfunction, including abnormal IFN- $y$ levels, considered to have a pivotal role in controlling LTBI. In fact, among ESRD patients, those on hemodialysis had a higher prevalence of TB, compared to other patient groups. According to Min et al., The probability of being infected with active TB during hemodialysis or peritoneal dialysis among ESRD patients was increased 4.44 ratio for hemodialysis patients and 5.17 ratio for peritoneal dialysis patients respectively. [14]. In ESRD patients and hemodialysis patients, there is a possibility that $\mathrm{T}$ cell dysfunction related to adaptive immunity may occur unlike normal healthy persons. It is therefore likely that the results of the IGRA test for diagnosing LTBI and the interpretation of the results are likely to be affected.

The aim of the present study was to evaluate the effectiveness of the diagnosis of LTBI using IGRA in a group at high risk for contracting active TB, whole blood samples from a total of 84 hemodialysis patients and 52 healthy non-TB subjects were collected and analyzed by currently available IGRA testing, QuantiFERON TB Gold In-Tube (QFT-GIT) assay (Qiagen, Hilden, Germany). Characteristics of MTBspecific Ag and T-cell mitogen (PHA) stimulated IFN- $\gamma$ release were compared between hemodialysis patients and healthy non-TB subjects.

\section{Methods}

\section{Study design and locations}

This study targeted patients receiving hemodialysis for approximately one year, from March 2017 to June 2018. A total of 84 hemodialysis patients and 52 healthy subjects were enrolled from Kosin University 
Gospel Hospital and Catholic University of Pusan, Busan, Republic of Korea, and their whole blood samples were collected and used for the present study. All participants provided written informed consent. The Institutional Ethics Committee of Catholic University of Pusan and Kosin University Gospel Hospital approved the study (approval numbers CUPIRB-2017-036 and KUGH 2017-11-042).

Case of enrolled hemodialysis patients were more than 31 years old with ESRD and were undergoing more than three month hemodialysis treatment or were HCs. Those with HIV infection, liver cirrhosis of Child-Pugh class $C$, cancer or autoimmune disease and those who had received chemotherapy within the last three months and who had any history of active TB treatment were excluded. In addition, the active TB group was excluded to study the difference in LTBI status in hemodialysis patients, a high-risk for TB group. Results of IGRA, MTB-specific Ag stimulated IFN- $\gamma$ release, and T-cell mitogen (PHA)-stimulated IFN-y release in the collected whole blood samples were compared between the two groups, hemodialysis patients and healthy non-TB subjects. Plasma was isolated from whole blood after MTB-specific antigen stimulation and stored at $-70^{\circ} \mathrm{C}$ until use.

\section{Interferon gamma release assay with QuantiFERON ${ }^{\circledR}$-TB gold in-tube (QFT-GIT)}

An IGRA test was performed on all participants enrolled in this study. IGRAs are whole-blood tests that can aid in diagnosing MTB infection by detecting IFN-y in human plasma samples. QFT-GIT assay (Qiagen) was used according to the manufacturer's instructions on samples from hemodialysis patients and from healthy individuals. Whole blood samples were divided into three QFT-IT collection tubes for nil (negative control), MTB-specific antigen stimulation, and T-cell mitogen stimulation (positive control). The nil control tube contained only the anticoagulant lithium heparin, used for determining the basal level of immune response of peripheral blood cells. The MTB-specific antigen tube contained anticoagulant and MTB-specific antigens, such as ESAT-6, CFP-10, and TB 7.7, used for detecting MTB-specific immune response. The mitogen control tube contained anticoagulant and T-cell mitogen (phytohemagglutinin; PHA), used for detecting immune cell function, as a positive control. Antigen stimulation should be performed within $3 \mathrm{~h}$ after peripheral blood collection. Antigen stimulation was performed during $24 \mathrm{~h}$ at $37^{\circ} \mathrm{C}$ for the QFT-IT (IFN-Y ELISA).

\section{Data interpretation of interferon gamma release assay}

The test results were interpreted using GFT-GIT ELISA software (version no. 2.43; Cellestis LTD. Victoria, Australia) and the cut-offs for diagnosis in the manufacturer's instructions were used. The test result was considered positive if the IFN- $\gamma$ level in the sample well, after stimulation with ESAT-6, CFP-10, and TB 7.7 was $0.35 \mathrm{IU} / \mathrm{ml}(0.42 \mathrm{ng} / \mathrm{mL})$, irrespective of the result for the positive control well. The test was considered negative if the IFN- $\gamma$ level was $0.35 \mathrm{IU} / \mathrm{ml}(0.42 \mathrm{ng} / \mathrm{mL})$ and the IFN- $\gamma$ level of the positive control well was $0.35 \mathrm{IU} / \mathrm{ml}(0.42 \mathrm{ng} / \mathrm{mL})$. The test result was considered indeterminate if the IFN- $\gamma$ level was $0.35 \mathrm{IU} / \mathrm{ml}(0.42 \mathrm{ng} / \mathrm{mL})$ in both antigen wells and $0.5 \mathrm{IU} / \mathrm{ml}(0.6 \mathrm{ng} / \mathrm{mL})$ in the mitogen control well.

\section{Statistical analysis}


Statistical analysis was performed using GraphPad prism, version 5.00 (GraphPad Software, San Diego, CA, USA). The significant difference in the results between the hemodialysis patients and the healthy individuals, which were predicted to be weaker, was calculated. In particular, the value of mitogen control, which is coated with a PHA that stimulates T-cells nonspecifically to secrete IFN- $\gamma$, is calculated as the difference between the hemodialysis patients and the healthy individuals, with $95 \%$ confidence intervals $(\mathrm{Cls})$, and the values of these groups were compared using the Mann-Whitney $\mathrm{U}$ test. A $P$ value less than 0.05 was considered statistically significant.

\section{Results}

\section{Characteristics of hemodialysis patients and healthy individuals}

The characteristics of the patients involved in this study are shown in Table 1. The mean age of hemodialysis patients was 61.1 years (range 31 - 90) and the male-to-female ratio was 43:41 (51.2\%:48.8\%), while the mean age of the healthy individuals was 23.9 years (range $22-35$ ) and the male-to-female ratio was $23: 29$ (44.2\%:55.8\%). The age of the hemodialysis patients was considerably higher than that of the healthy individuals. In addition, only $57(67.9 \%)$ of the hemodialysis patients had received BCG vaccine, while all the healthy subjects had received the vaccine. Cases reporting having been in contact with tuberculosis patients were $13(15.4 \%)$ of the hemodialysis patients, and there were only $6(7.1 \%)$ patients with radiological lesions among the hemodialysis patients.

\section{GFT-GIT results for hemodialysis patients and healthy individuals}

A comparison of the IGRA test between hemodialysis patients and the healthy individuals revealed a significant difference, as shown in Table 2. Among 84 hemodialysis patients, all satisfied the study criteria for IGRA, 34 (40.4\%) were positive for IGRA, 49 (58.3\%) were negative and one was indeterminate. In the healthy individuals, the sensitivity of the test was very high as 48 of 52 subjects showed negative results. As a result, the QFT-GIT positivity rates of hemodialysis patients and healthy subjects were 34/84 $(40.4 \%)$ and $4 / 52(7.6 \%)$, respectively, thus reflecting that IGRA positivity was significantly higher in hemodialysis patients than in healthy individuals. To differentiate between LTBI and non-LTBI status in hemodialysis patients, indeterminate patients were excluded form subsequent studies.

\section{Comparison of MTB-specific antigen-stimulated IFN- $ү$ production between hemodialysis patients and healthy individuals}

The mean values of MTB-specific Ag-stimulated IFN- $y$ in hemodialysis patients with LTBI and non-LTBI status in hemodialysis patients, healthy individuals were $1.85 \mathrm{IU} / \mathrm{mL}(4.44 \mathrm{ng} / \mathrm{mL})$ and $0.028 \mathrm{IU} / \mathrm{mL}$ $(0.067 \mathrm{ng} / \mathrm{mL})$ and $0.255 \mathrm{IU} / \mathrm{mL}(0.612 \mathrm{ng} / \mathrm{mL})$ respectively (Figure 1$)$. These results showed that the IFN- $\gamma$ value was significantly higher in hemodialysis patients with $\mathrm{LTBl}$; however, the T-cell mitogenstimulated IFN- $\gamma$ value was much higher in healthy individuals. Based on these results, we confirmed that T-cell function in hemodialysis patients was reduced as compared to healthy subjects (Figure 2). Table 3 shows that in hemodialysis patients with LTBI, the rate of IFN-y stimulated with TB antigen was higher 
than $0.5 \mathrm{IU} / \mathrm{mL}(1.2 \mathrm{ng} / \mathrm{mL})$ in 30 cases $(88.2 \%)$ and lower than $0.5 \mathrm{IU} / \mathrm{mL}(1.2 \mathrm{ng} / \mathrm{mL})$ in 4 cases $(11.8 \%)$. On the other hand, in healthy individuals there were 4 cases $(7.6 \%)$ and 48 cases $(92.3 \%)$ respectively.

\section{Comparison of results from MTB-specific Ag stimulated IFN-y levels and T-cell mitogen (PHA)-stimulated IFN- $y$ levels between hemodialysis patients and healthy individuals.}

The correlation graph of MTB-specific Ag stimulated IFN-y levels and T-cell mitogen(PHA)stimulated IFN-y levels is shown in Figure 3. Of the 83 hemodialysis patients, 33 (39.8\%) were T-cell mitogen(PHA)-stimulated IFN- $y$ levels below 10. 19 (38.8\%) in hemodialysis patients with LTBI and 14 $(41.2 \%)$ in non-LTBI status in hemodialysis patients respectively (Figure 3-A). On the other hand, none of the healthy individuals had T-cell mitogen(PHA)-stimulated IFN- $y$ levels below 10 (Figure 3-B).

\section{Discussion}

TB is one of the top 10 causes of death in the world, and the leading cause from a single infectious agent (ranking above HIV/AIDS) [7]. Millions of people continue to fall sick with TB each year [15]. Therefore, there is a need for a method to quickly diagnose those with a high risk of TB. Delayed diagnosis in this situation is an important issue contributing to the high burden and transmission of TB in developing countries [16].

In a previous study, the performance of QFT-GIT was not excellent in patients with impaired immune function, and the results were unclear [17]. Recently, the relationship between TB and the immune status of patients has been revealed, and directions for diagnosis based on the immune status have been suggested [18]. Another study has shown that IGRA testing is useful in identifying LTBI in patients with rheumatic disease, one of the groups at high risk of TB [19]. The population undergoing hemodialysis is expanding and is suggested as a high priority group for LTBI treatment, given their increased TB risk [20]. Immunologically, renal disease (RD) is associated with some disorders in both innate and adaptive immune systems in such a way that there is coexistence of both immune activation and immune suppression [21]. Immune response to MTB infection is primarily mediated by T-cells [22].

Recent studies have shown that hemodialysis patients have a higher infection rate because their immune system is weakened [23]. This study investigated the risk of TB in patients undergoing hemodialysis and in healthy individuals and compared them with LTBI status indicated by QFT-GIT. The LTBI positive rate was significantly higher in the hemodialysis patients than in the healthy individuals. Table 3 shows that more IFN- $y$ is secreted in T-cells that have been exposed to TB in hemodialysis patients than in the healthy individuals. In hemodialysis patients whose mitogen-nil values were less than $10 \mathrm{IU} / \mathrm{mL}$ $(24 \mathrm{ng} / \mathrm{mL})$, the immune responses of the T-cells were lower than those of the healthy individuals. As shown in Table 4, in the healthy individuals, no patients with a T-cell mitogen-stimulated IFN-y level lower than 10 were observed. However, in hemodialysis patients with LTBI, 20 out of 34 (58.8\%) showed lower than 10. In particular, non-LTBI status in hemodialysis patients, 30 out of 49 showed lower than 10 . These results suggest that T-cell mitogen-stimulated IFN- $y$ levels are lower than 10 and that T-cell mediated immunity is lowered, resulting in a false negative [24]. Other studies have reported alteration of adaptive 
immune system for ESRD patients. For example, in the ESRD patient group, the vaccination response to TB or the tuberculin skin test to diagnose LTBI resulted in weak or no response [25]. Compared with the results of this study, the QFT-GIT assay also shows similar results for ESRD patients.

Impaired cellular immunity may explain anergy and high rates of false negative results of IGRA in hemodialysis patients [26]. In fact, many ESRD patients and hemodialysis patients are known to have symptoms of uremia-induced immune system and acquired immune system, resulting in various infections and complications [25]. In vitro studies have shown that uremic milieu caused by ESRD reduces $T$ cell function and population. It also has been shown to influence the formation of a variety of pro-inflammatory cytokines, TNF-a, IL-12 or INF-y, which are secreted by T cells [27-28]. The results of this study also confirm that the IFN- $\gamma$ concentration is decreased during stimulation by mitogen, possibly due to uremic milieu in ESRD patients. Therefore, further studies on the correlation between serum concentration of urea levels and QFT-GIT assay results are needed. For the ESRD patients, it may be possible to use the serum concentration of urea as an auxiliary index in the interpretation of the QFT-GIT assay results.

In this study, among the negative cases in hemodialysis patients there may be positives, that is, there are likely to be false negatives due to the immune response of T-cells being reduced. These results suggest the possibility of false negatives in the QFT-GIT assay using enzyme-linked immunosorbent assays to measure the antigen-specific production of IFN- $y$ using T-cells in whole blood. Thus, interpretation of IGRA results among hemodialysis patients should be undertaken with caution before treatment for LTBI.

\section{Conclusion}

The reliability of QFT-GIT in patients with T-cell-mediated immune responsiveness is not high; additional analyses using alternative immune markers or inflammatory markers, and qRT-PCR that simultaneously detects the mRNA expressions of TB-related proinflammatory immune biomarkers may increase the reliability of the test and be more helpful for the rapid screening and detection of groups at high risk for TB, including hemodialysis patients. Furthermore, screening for LTBI using nonimmunologic methods may help combat TB, given that the immune system has already been compromised.

\section{References}

1. Daley CL. The Global Fight Against Tuberculosis. Thorac Surg Clin. 2019;29(1):19-25. doi:10.1016/j.thorsurg.2018.09.010

2. World Health Organization. Global tuberculosis report 2018. France: World Health Organization, 2018.

3. Floyd K, Glaziou P, Zumla A, Raviglione M. The global tuberculosis epidemic and progress in care, prevention, and research: an overview in year 3 of the End TB era. Lancet Respir Med. 2018;6(4):299314. doi:10.1016/S2213-2600(18)30057-2 
4. Cruz AT, Starke JR. A current review of infection control for childhood tuberculosis. Tuberculosis (Edinb). 2011;91 Suppl 1:S11-S15. doi:10.1016/j.tube.2011.10.004

5. Keshavjee S, Amanullah F, Cattamanchi A, Chaisson R, Mdobos K, Fox G, et al. Moving toward Tuberculosis Elimination. Critical Issues for Research in Diagnostics and Therapeutics for Tuberculosis Infection. Am J Respir Crit Care Med. 2019;199(5):564-571. doi:10.1164/rccm.2018061053PP

6. Amorim RF, Viegas ERC, Carneiro AJV, Esberard BC, Chinem ES, Correa RS, et al. Superiority of Interferon Gamma Assay Over Tuberculin Skin Test for Latent Tuberculosis in Inflammatory Bowel Disease Patients in Brazil. Dig Dis Sci. 2019;64(7):1916-1922. doi:10.1007/s10620-019-5475-3

7. Klautau GB, da Mota NVF, Salles MJC, Burattini MN, Rodrigues DS. Interferon-y release assay as a sensitive diagnostic tool of latent tuberculosis infection in patients with HIV: a cross-sectional study. BMC Infect Dis. 2018;18(1):585. Published 2018 Nov 19. doi:10.1186/s12879-018-3508-8

8. Doan TN, Eisen DP, Rose MT, Slack A, Stearnes G, McBryde ES. Interferon-gamma release assay for the diagnosis of latent tuberculosis infection: A latent-class analysis. PLoS One. 2017;12(11):e0188631. Published 2017 Nov 28. doi:10.1371/journal.pone.0188631

9. Sharma SK, Vashishtha R, Chauhan LS, Sreenivas V, Seth D. Comparison of TST and IGRA in Diagnosis of Latent Tuberculosis Infection in a High TB-Burden Setting. PLoS One. 2017;12(1):e0169539. Published 2017 Jan 6. doi:10.1371/journal.pone.0169539

10. Pai M, Denkinger CM, Kik SV, Rangaka MX, Zwerling A, Oxlade O, et al. Gamma interferon release assays for detection of Mycobacterium tuberculosis infection. Clin Microbiol Rev. 2014;27(1):3-20. doi:10.1128/CMR.00034-13

11. Kobashi Y, Shimizu H, Ohue Y, Mouri K, Obase Y, Miyashita N, et al. Comparison of T-cell interferongamma release assays for Mycobacterium tuberculosis-specific antigens in patients with active and latent tuberculosis. Lung. 2010;188(4):283-287. doi:10.1007/s00408-010-9238-3

12. Bertholet S, Ireton GC, Ordway DJ, Windish HP, Pine SO, Kahn M, et al. A defined tuberculosis vaccine candidate boosts BCG and protects against multidrug-resistant Mycobacterium tuberculosis. Sci Transl Med. 2010;2(53):53ra74. doi:10.1126/scitransImed.3001094

13. Mandalakas AM, Detjen AK, Hesseling AC, Benedetti A, Menzies D. Interferon-gamma release assays and childhood tuberculosis: systematic review and meta-analysis. Int $\mathrm{J}$ Tuberc Lung Dis. 2011;15(8):1018-1032. doi:10.5588/ijtld.10.0631

14. Min J, Kwon SK, Jeong HW, Han JH, Kim YJ, Kang M, et al. End-stage Renal Disease and Risk of Active Tuberculosis: a Nationwide Population-Based Cohort Study. J Korean Med Sci. 2018;33(53):e341. Published 2018 Dec 13. doi:10.3346/jkms.2018.33.e341

15. Lee SH, Kim HJ, Park SJ, Kim TH, Park SJ, Kang SW, et al. Serial interferon-gamma release assays for latent tuberculosis in dialysis patients with end stage renal disease in a Korean population. BMC Infect Dis. 2015;15:381. Published 2015 Sep 21. doi:10.1186/s12879-015-1117-3 
16. Shiferaw MB, Zegeye AM. Delay in tuberculosis diagnosis and treatment in Amhara state, Ethiopia. BMC Health Serv Res. 2019;19(1):232. Published 2019 Apr 16. doi:10.1186/s12913-019-4056-7

17. González-Moreno J, García-Gasalla M, Losada-López I, Luna CC, Viladrich IM, Fernández-Baca V, et al. IGRA testing in patients with immune-mediated inflammatory diseases: which factors influence the results?. Rheumatol Int. 2018;38(2):267-273. doi:10.1007/s00296-017-3852-9

18. Meng Q, Sayin I, Canaday DH, Mayanja-Kizza H, Baseke J, Toossi Z. Immune Activation at Sites of HIV/TB Co-Infection Contributes to the Pathogenesis of HIV-1 Disease. PLoS One. 2016;11(11):e0166954. Published 2016 Nov 21. doi:10.1371/journal.pone.0166954

19. Nozawa T, Mori M, Nishimura K, Sakurai N, Kikuchi M, Hara R, et al. Usefulness of two interferon- $\gamma$ release assays for rheumatic disease. Pediatr Int. 2016;58(5):347-352. doi:10.1111/ped.12885

20. Chin-Chung shu. Risk of tuberculosis in dialysis population: Revising the predictive value of interferon-gamma releasing assay. European Respiratory Society. 2016;48:PA2698. doi.org/10.1183/13993003.congress-2016.PA2698

21. Sharif MR, Chitsazian Z, Moosavian M, Raygan F, Nikoueinejad H, Sharif AR, et al. Immune disorders in hemodialysis patients. Iran J Kidney Dis. 2015;9(2):84-96.

22. Zhao N, Sun JY, Xu HP, Sun FY. Early Diagnosis of Tuberculosis-Associated IgA Nephropathy with ESAT-6. Tohoku J Exp Med. 2017;241(4):271-279. doi:10.1620/tjem.241.271

23. Lamarche C, Iliuta IA, Kitzler T. Infectious Disease Risk in Dialysis Patients: A Transdisciplinary Approach. Can J Kidney Health Dis. 2019;6:2054358119839080. Published 2019 Apr 29. doi:10.1177/2054358119839080

24. Kim YJ, Kang JY, Kim SI, Chang MS, Kim YR, Park YJ. Predictors for false-negative QuantiFERON-TB Gold assay results in patients with extrapulmonary tuberculosis. BMC Infect Dis. 2018;18(1):457. Published 2018 Sep 10. doi:10.1186/s12879-018-3344-x

25. Kato S, Chmielewski M, Honda H, Pecoits-Filho R, Matsuo S, Yuzawa Y, et al. Aspects of immune dysfunction in end-stage renal disease. Clin J Am Soc Nephrol. 2008;3(5):1526-1533. doi:10.2215/CJN.00950208

26. Takhar RP, Mirdha K, Purohit G, Maan L, Bainara MK. Impact of HIV Co-Infection on Clinical Presentation in Patients with TB and Correlation of the Findings with Level of Immune Suppression. Tanaffos. 2018;17(3):188-197.

27. Meuer SC, Hauer M, Kurz P, Meyer zum Büschenfelde KH, Köhler H. Selective blockade of the antigenreceptor-mediated pathway of $\mathrm{T}$ cell activation in patients with impaired primary immune responses. J Clin Invest. 1987;80(3):743-749. doi:10.1172/JCI113129

28. Stachowski J, Pollok M, Burrichter H, Spithaler C, Baldamus CA. Signalling via the TCR/CD3 antigen receptor complex in uremia is limited by the receptors number. Nephron. 1993;64(3):369-375. doi:10.1159/000187356

\section{Declarations}




\section{Acknowledgement}

This study was supported by the Basic Science Research Program through the National Research Foundation of Korea (NRF) funded by the Ministry of Education (NRF-2016R1C1B108888 and -2020R1C1007169) and the Brain Busan 21 Plus project.

\section{Funding}

This research did not receive any specific grant from funding agencies in the public, commercial, or not for profit sectors.

\section{Availability of data and materials}

The data analysed during this study are included in this paper. Some of the datasets are available from the corresponding author upon reasonable request

\section{Author's contributions}

Heechul Park conceptualized, designed the paper, analyzed, wrote and drafted the paper. Heechul park, Ye Na Kim, Sung-Bae Park, Junseong Kim, Jaewon Lim and Jungho Kim collected the data and reviewed the paper critically. Sunghyun Kim and Ji Young Park also analyzed the data. All authors read and approved the final paper.

\section{Ethics declarations}

\section{Ethics approval and consent to participate}

The study was approved by the institutional ethics committee of Catholic University of Pusan and Kosin University Gospel Hospital (approval numbers CUPIRB-2017-036 and KUGH 2017-11-042).

\section{Consent for publication}

Not applicable. 


\section{Competing interests}

The authors declare that they have no competing interest

\section{Tables}

Table 1

Characteristic of study participants

\begin{tabular}{|c|c|c|c|}
\hline Characteristic & & Hemodialysis patients, $\mathrm{n}(\%)$ & Healthy individuals, $\mathrm{n}(\%)$ \\
\hline \multirow[t]{5}{*}{ Age } & & $\begin{array}{l}\text { (median = 61.1 SD } \pm 11.5, \text { range }=31- \\
90)\end{array}$ & $\begin{array}{l}\text { (median }=23.9 \mathrm{SD} \pm 2.7, \text { range }=22- \\
35 \text { ) }\end{array}$ \\
\hline & $20 \mathrm{~s}$ & $0(0 \%)$ & $50(96.2 \%)$ \\
\hline & $\begin{array}{l}30- \\
40 s\end{array}$ & $12(14.2 \%)$ & $2(3.8 \%)$ \\
\hline & $\begin{array}{l}50- \\
60 s\end{array}$ & $52(62.1 \%)$ & $0(0 \%)$ \\
\hline & $>70 \mathrm{~s}$ & $20(23.7 \%)$ & $0(0 \%)$ \\
\hline \multirow[t]{2}{*}{ Sex } & Male & $43(51.2 \%)$ & $23(44.2 \%)$ \\
\hline & Female & e $41(48.8 \%)$ & $20(55.8 \%)$ \\
\hline \multicolumn{2}{|l|}{ Body Mass Index (BMI) } & $\begin{array}{l}\text { median }=21.58 S D \pm 3.48 \\
\text { range }=14.15 \text { to } 31.07\end{array}$ & $\begin{array}{l}\text { median }=21.84 \mathrm{SD} \pm 2.55 \\
\text { range }=17.44 \text { to } 27.44\end{array}$ \\
\hline $\begin{array}{l}\text { BCG scar of } \\
\text { vaccination }\end{array}$ & & $57(67.9 \%)$ & $52(100 \%)$ \\
\hline Contact TB history & & $13(15.4 \%)$ & $0(0 \%)$ \\
\hline Any radiological & & $6(7.1 \%)$ & $0(0 \%)$ \\
\hline Total & & 84 (100\%) & $52(100 \%)$ \\
\hline
\end{tabular}


Table 2

IGRA results for hemodialysis patients and healthy individuals

\begin{tabular}{|c|c|c|}
\hline & IGRA & $\mathrm{n}(\%)$ \\
\hline \multirow{3}{*}{$\begin{array}{l}\text { Hemodialysis patients } \\
(\mathrm{n}=84)\end{array}$} & sPositive & $34(40.4 \%)$ \\
\hline & \multicolumn{2}{|c|}{ Indeterminate1 (1.1\%) } \\
\hline & Negative & 49 (58.3\%) \\
\hline \multirow{3}{*}{$\begin{array}{l}\text { Healthy individuals } \\
(n=52)\end{array}$} & Positive & $4(7.6 \%)$ \\
\hline & \multicolumn{2}{|c|}{ Indeterminate $0(0 \%)$} \\
\hline & Negative & $48(92.3 \%)$ \\
\hline
\end{tabular}

Table 3

Comparison of IFN-y production TB antigen stimulated

\begin{tabular}{|c|c|c|c|c|}
\hline & TB Ag-Nil & $n(\%)$ & Mitogen-I & )$n(\%)$ \\
\hline Hemodialysis patients LTBI & $\geq 5$ & $3(8.8 \%)$ & $<5$ & $2(5.9 \%)$ \\
\hline$(n=34)$ & $\geq 1,<5$ & $14(41.2 \%$ & )$\geq 5,<10$ & 12 (35.3\%) \\
\hline & $\geq 0.5,<1$ & $13(38.2 \%$ & $\geq 10$ & $20(58.8 \%)$ \\
\hline & $<0.5$ & $4(11.8 \%)$ & & \\
\hline Hemodialysis patients nonLT & $\mid \geq 5$ & 0 & $<5$ & $1(2 \%)$ \\
\hline$(n=49)$ & $\geq 1,<5$ & 0 & $\geq 5,<10$ & $18(36.7 \%)$ \\
\hline & $\geq 0.5,<1$ & 0 & $\geq 10$ & $30(61.2 \%)$ \\
\hline & $<0.5$ & $49(100 \%)$ & & \\
\hline Normal subjects & $\geq 5$ & $2(3.8 \%)$ & $<5$ & $0(0 \%)$ \\
\hline$(n=52)$ & $\geq 1,<5$ & $1(1.9 \%)$ & $>5,<10$ & $0(0 \%)$ \\
\hline & $\geq 0.5,<1$ & $1(1.9 \%)$ & $\geq 10$ & $52(100 \%)$ \\
\hline & $<0.5$ & $48(92.3 \%$ & & \\
\hline
\end{tabular}


Figures

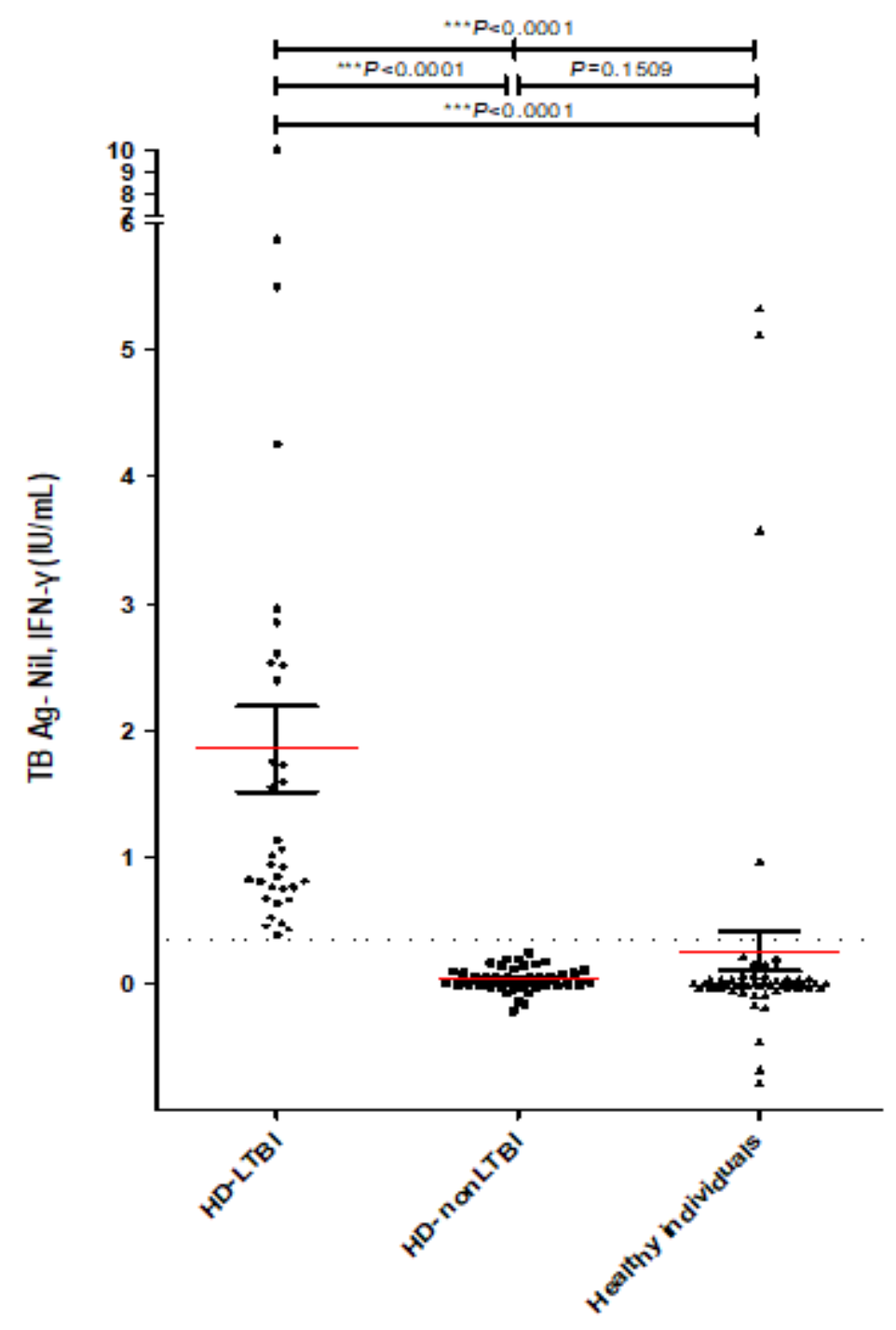

Figure 1

MTB-specific Ag stimulated IFN- $y$ levels in hemodialysis patients and normal subjects. HD-LTBI : LTBI status in hemodialysis patients ( $n=34)$; HD-nonLTBI : non LTBI status in hemodialysis patients $(n=49)$; Healthy individuals $(n=52)$. The red line is the Mean with SEM value of each group. 


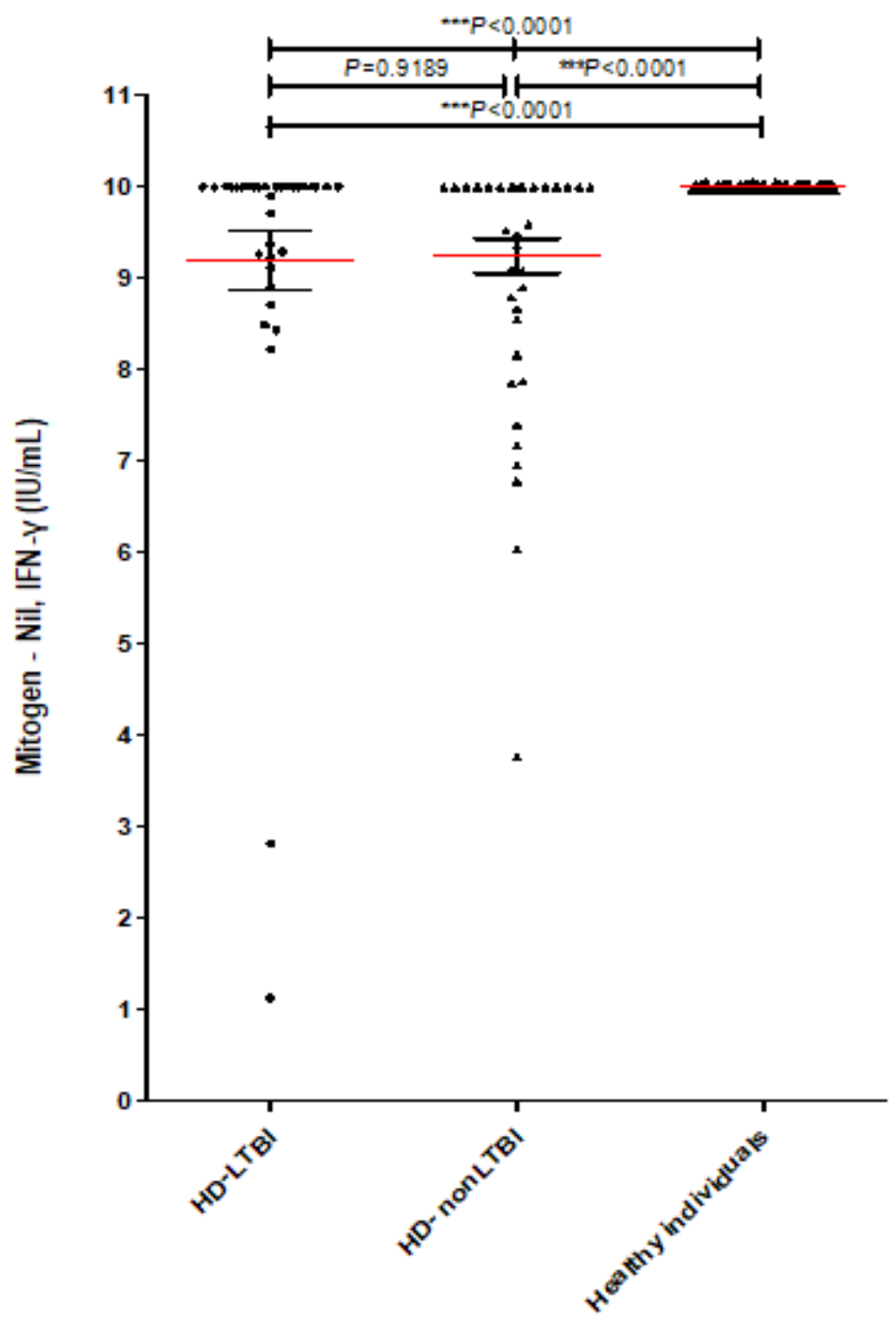

Figure 2

T-cell mitogen (PHA)-stimulated IFN-y levels in hemodialysis patients and normal subjects. 

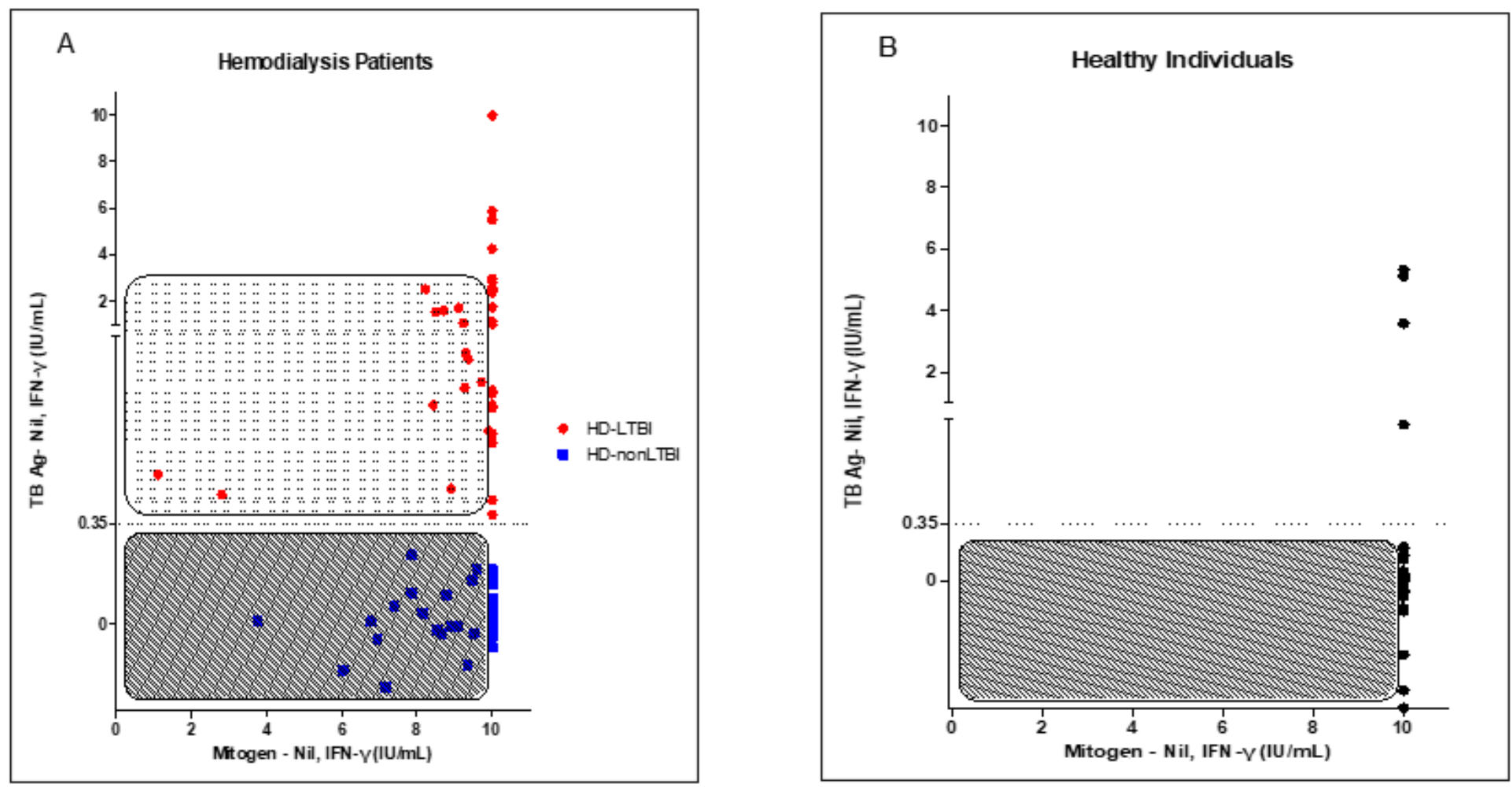

\section{Figure 3}

Comparison of results from MTB-specific Ag stimulated IFN- $\gamma$ levels and T-cell mitogen (PHA)-stimulated IFN- $y$ levels between hemodialysis patients $(A)$ and healthy individuals $(B)$. gray box : the part of abnormal T cell capability (41.2\% in HD-LTBI and 38.8\% in HD-nonLTBI) 